\title{
The nervous system and pH
}

\author{
Kevin Carlin \\ Education Department, Central Texas Veterans Health Care System Temple, Temple, USA \\ Email: Kevin.Carlin@va.gov
}

Received 22 October 2013; revised 15 November 2013; accepted 22 November 2013

Copyright (C) 2013 Kevin Carlin. This is an open access article distributed under the Creative Commons Attribution License, which permits unrestricted use, distribution, and reproduction in any medium, provided the original work is properly cited.

\begin{abstract}
The mix of cellular pumps, channels, transporters, and isoenzymes is genetically inherited. However, the environment has the ability to impact the cellular pumps, channels, transporters, and isoenzymes to some degree. Cellular pumps, channels, transporters and isoenzymes help control cellular $\mathrm{pH}$ and vice versa. Therefore possibly the $\mathbf{p H}$ in the nervous system is more variable than previously believed. If so, that could explain some of the changes we see in the nervous system.
\end{abstract}

Keywords: Central Nervous System; pH; Genetic Predisposition; Environmental Triggers; Cellular Pumps; Channels; Transporters; Isoenzymes; Dementia; Parkinsons Disease; Traumatic Brain Injury

\section{INTRODUCTION}

Why do cells have cell membranes other than control what is outside the cell versus inside the cell. We have cellular pumps/channels-transporters and isoenzymes to control the inside versus the outside. Possibly one of the things being controlled is $\mathrm{pH}$. The level of $\mathrm{pH}$ would impact cellular pumps/channels-transporters and isoenzymes as well as vice versa. Genetically we inherit a specific combination of these but they can also be impacted by the environment... answering the age old question of genetic predisposition and environment triggers.

\section{REVIEW/DISCUSSION}

Several years ago a group of neurologists noted that a topical hemostatic agent made of oxidized cellulose widely used in neurosurgery was inducing a focal neuropathy [1]. They found no neurotoxin present but rather significant acidity associated with the product and a dose-dependent effect. They noted if the acidosis was neutralized no neuropathy developed in sciatic nerves. Because the nervous system needs to generate electrical charges, it makes the system vulnerable to anything that impacts the cellular pumps/channels-transporters and isoenzymes.

Obviously nerves throughout the body generate electrical charges. Electrical change may be more important in the neurological systems of the body then in many other parts. For example, even the vascular endothelial cells in the central nervous system are different than most endothelial cells in the body because of their barrier status with electrical resistance as high as $149.0+/-10.3$ $\mathrm{ohm} \mathrm{cm}^{2}$, versus for example $34.8+/-6.8 \mathrm{ohm} \mathrm{cm}^{2}$ in the aortic endothelial cells [2]. A pH change could impact the maintaining of this electrical resistance difference. Some would say as we age, the blood brain barrier does not work as well [3]... perhaps $\mathrm{pH}$ is not as well maintained as we age. The blood brain barrier is well known to begin to fail with infection and/or tumor growth. Both are well known to be associated with acidosis. On the other hand hydrocortisone has been reported to strengthen the tight junctions by increasing the electrical resistance [4]. The $\mathrm{Na}-\mathrm{H}$ exchanger activity level is known to be impacted by glucocorticoids. Glucocorticoids increase the $\mathrm{Na}-\mathrm{H}$ exchange and decrease the $\mathrm{Na}$ gradient [5]. This could cause a $\mathrm{pH}$ change.

Awake versus asleep has to do with the suprachiasmatic nucleus of the hypothalamus. Temazepam (Restoril) is a well-known sleep inducing agent whose mechanism of action is increased neuronal membrane permeability to chloride ions. The shift in chloride ions results in hyperpolarization and thus less excitable state. Lithium a well-known medication for bipolar disease alters cation transport across the cell membrane of the nerve cell. Phenytoin a well-known anticonvulsant medication works by increasing efflux or decreasing influx of sodium ions across cell membranes. How could this not be involved with the cellular pumps/channels-transporters and isoenzymes and thus $\mathrm{pH}$ indirectly?

Some substances are well known to impact the functioning of the central nervous system... for example alcohol. In chronic alcoholics one group found decreased functioning of membrane bound enzyme $\mathrm{Na}^{+}, \mathrm{K}+\mathrm{AT}-$ 
Pase activity in red blood cells [6]. Obviously this could impact the $\mathrm{pH}$ of the cell.

Strong ions such as metal could conceivably impact the cellular pumps/channels-transporters and isoenzymes. Indeed that is possibly what we see with neurological problems with Wilson's disease which has an accumulation of copper or dialysis encephalopathy due to aluminum. Finally if $\mathrm{pH}$ changes enough there could be a charge generated which could impact movement. A charge could obviously cause attraction or repulsion. Receptors and ligands could be impacted.

Hyperventilation causes hypocapnia which changes the $\mathrm{pH}$ to alkalinity. It also causes loss of consciousness of the central nervous system. Delirium occurs with electrolyte abnormalities such as hyponatremia and hypercalcemia and reverses with the correction of the electrolyte abnormality. These conditions would obviously impact $\mathrm{pH}$ through their impact upon the cellular pumps/ channels-transporters and isoenzymes.

Perhaps traumatic brain injury is a matter of small micro tears in the cell membrane. This would make it difficult to control the inside versus the outside. If nerves electrically misfired it would be like a computer electrically misfiring. The output would be changed. Post-traumatic seizures and epilepsy could be because the cell membrane had multiple small tears compromising the ability of the cellular pumps/channels-transporters and isoenzymes to function appropriately thus changing cellular metabolism and function. The products of the cells could change due to different isoenzymes being more active while some less active. Mitochondria function could change due to the background $\mathrm{pH}$ level changes.

Memory must be influenced by electrical conduction since external shocks cause memory issues as does endogenous electrical abnormalities such as seizures. Dramatic electrolyte changes appear to induce seizures. The seizure threshold may be lowered by impacting the cellular pumps/channels-transporters and isoenzymes though a $\mathrm{pH}$ change.

Electrical stimulation upon the central nervous system is known to stimulate return of a memory. Could memory be an endothermic chemical reaction awaiting the extra energy to drive the reaction which then releases the memory and energy? Indeed neural activity increases the brain's temperature [7]. Recent memory could be exothermic but remote memory would be endothermic requiring a direct measured electrical input to release.

The hippocampus is involved in processing and storage of memory. High doses of glucocorticosteroids cause problems in memory.Glucocorticosteroids have actually been shown to cause hippocampusatrophy [8]. Remember as noted above, the $\mathrm{Na} / \mathrm{H}$ exchanger activity level is known to be impacted by glucocorticoids. Glucocorticoids increase the $\mathrm{Na}-\mathrm{H}$ exchange and decrease the $\mathrm{Na}$ gradient. This could cause a pH change.

Wernicke's encephalopathy B1 thiamine deficiency is associated with an enzyme functioning at a decreased level... transketolase. Thiamine is a cofactor. But also the optimum $\mathrm{pH}$ of the enzyme transketolase is $7.8-8.0$ [9]. Identical twins are more likely than fraternal twins to get Wernicke's encephalopathy with alcohol use. Perhaps this is the impact of the genetic makeup of the cellular pumps/channels-transporters and isoenzymes.

With aging of the brain there is atrophy. Could this be a slow progressive loss of the function of the cellular pumps/channels-transporters and isoenzymes? Apoptosis is associated with acidosis. Dementia could be a building up of byproducts due to the above failure. Vascular dementia even before infarction could be a progressive trend downward in $\mathrm{pH}$ due to ischemia. There is a familial predisposition to most types of dementia. This would correlate with the genetic predisposition toward a specific cellular pumps/channels-transporters and isoenzymes mixture. Dementia in general has been known for years to be associated with decreased function of the enzyme choline acetyl transferase... the optimum $\mathrm{pH}$ of the enzyme is 8.3 [10] which would be a problem if the central nervous system was trending more acidic. Finally remember Parkinsons Lewy bodies are eosinophilic (acid stain that binds to items that are basic). Possibly this is an attempt to return to homeostasis. Lewy bodies are also present in other degenerative diseases.

\section{CONCLUSION}

Just as the old name for parts of the pituitary were acidophils and basophils, neither of the above may be a smoking gun and thus cause a conviction but it should be enough circumstantial evidence to warrant an investigation. Remember all that stands between us and loss of our memory are a thin membrane.

\section{REFERENCES}

[1] Nagamatsu, M., Podratz, J., Windebank, A.J. and Low, P.A. (1997) Acidity is involved in the development of neuropathy caused by oxidized cellulose. Journal of the Neurological Sciences, 146, 97-102. http://dx.doi.org/10.1016/S0022-510X(96)00295-X

[2] Siesjo, B.K. (1985) Acid-base homeostasis in the brain: Physiology, chemistry, and neurochemical pathology. Progress in Brain Research, 63, 121-154. http://dx.doi.org/10.1016/S0079-6123(08)61980-9

[3] Enciu, A., Gherghiceanu, M. and Popescu, B.O. (2013) Triggers and effectors of oxidative stress at the bloodbrain barrier level: Relevance for brain ageing and neurodegeneration. Oxidative Medicine and Cellular Longevity, published online 10.1155/2013/297512.

[4] Kroll, S., El-Gindi, J., Thanabalasundaram, G., Panpum- 
thong, P., Schrot, S., Hartmann, C. and Galla, H. (2009) Control of the blood-brain barrier by glucocorticoids and the cells of the neurovascular unit. Annals of the New York Academy of Sciences, 1165, 228-239.

http://dx.doi.org/10.1111/j.1749-6632.2009.04040.x

[5] Freiberg, J.M., Kinsella, J. and Sacktor B. (1982) Glucocorticoids increase the $\mathrm{Na}+-\mathrm{H}+$ exchange and decrease the $\mathrm{Na}+$ gradient-dependent phosphate-uptake systems in renal brush border membrane vesicles. Proceedings of the National Academy of Sciences of the USA Biochemistry, 79, 4932-4936.

http://dx.doi.org/10.1073/pnas.79.16.4932

[6] Maturu, P., Vaddi D.R., Pannuru, P. and Nallanchakravarthula, V. (2013) Modification of erythrocyte membrane proteins, enzymes and transport mechanisms in chronic alcoholics: An in vivo and in vitro study. Alcohol and Alcoholism. http://dx.doi.org/10.1093/alcalc/agt071

[7] Kiyatkin, E.A., Brown, P.L. and Wise, R.A. (2002) Brain temperature fluctuation: A reflection of functional neural activation. European Journal of Neuroscience, 16, 164168. http://dx.doi.org/10.1046/j.1460-9568.2002.02066.x

[8] Sapolsky, R.M. (2000) Glucocorticoids and hippocampal atrophy in neuropsychiatric disorders. Archives of General Psychiatry, 57, 925-935.

http://dx.doi.org/10.1001/archpsyc.57.10.925

[9] Masri, S.W., Muslim, A. and Gubler, C.J. (1988) Isolation of transketolase from rabbit liver and comparison of some of its kinetic properties with transketolase from other sources. Comparative Biochemistry and Physiology, 90B, 167-172.

[10] Peng, J.H., McGeer, P.L. and McGeer, E.G. (1986) Membrane-bound choline acetyltransferase from human brain: Purification and properties. Neurochemical Research, 11, 959-971. http://dx.doi.org/10.1007/BF00965586 